\title{
Medicare needs a tune-up, says CMA president
}

Published at www.cmaj.ca on May 12

$\mathrm{M}$ any Canadians are proud of their health care system, but that doesn't mean medicare couldn't use a major tune-up. That was the message Canadian Medical Association President Dr. Anne Doig delivered to the Canadian Club in Ottawa, Ontario, May 11.

"We defend medicare with the same fervour that we protect all our other national symbols - in fact, even more than some," Doig said. "However, like many icons, what was once a shining symbol has become a little battered and tarnished."

The health needs of Canadians have changed dramatically since universal health insurance was introduced in 1961; to remain sustainable the health care system must likewise change, said Doig.

Canada's health care system is lacking in many areas, said the family physician from Saskatoon, Saskatchewan. For instance, Canada's hospital occupancy rate of $91 \%$ is higher than that of any of the 30 other countries in the Organisation for Economic Co-operation Development. This means Canadian hospitals do not have the capacity to handle fluctuations in illness rates.

"Needless to say, running hospitals in which hallway nursing is the norm is unacceptable."

Other major problems include a scarcity of long-term care facilities and home-care services, which has resulted in $25 \%-30 \%$ of acute-care beds being occupied by patients who need long-term care, and the rapid rise of spending on prescription drugs. In 2009 , drug costs accounted for $16 \%$ of national health care expenditures, second only to spending on hospitals. As Canada's population ages, spending on drugs is expected to rise for years to come.

"We need to manage our system better," said Doig. "We need to focus on quality. And we need to adopt and adapt to new technologies."

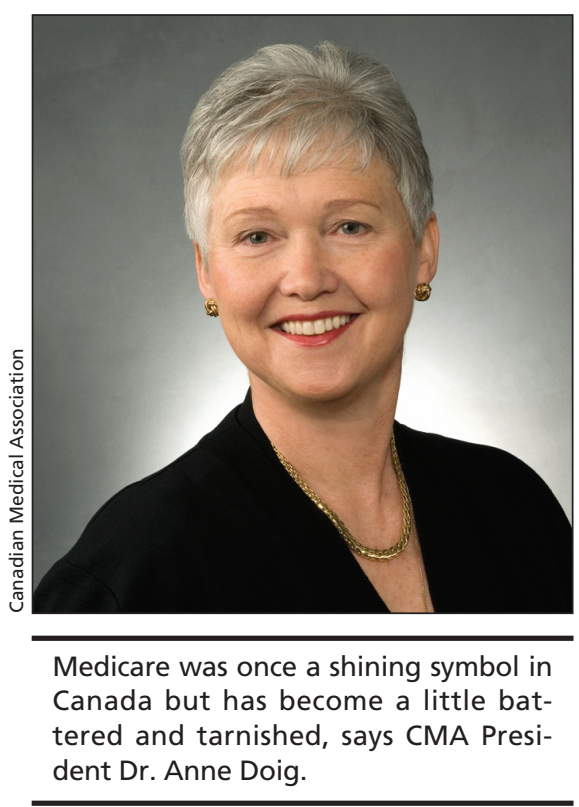

But the foundation for a new-andimproved health care system, said Doig, still rests on the five principles of the Canada Health Act:

- Universality: Several Canadian population groups, particularly those in socially and economically disadvantaged communities, have inadequate access to health services. This must change, said Doig, because it makes the principle of universality "ring hollow."

- Comprehensiveness: There is a lack of clarity in Canada about what constitutes a "medically necessary" service, said Doig. Also, seniors' drug coverage and home care account for about a quarter of public spending yet are not subject to the Canada Health Act. The inconsistency of employment-based plans for extended health benefits is also a problem, said Doig.

- Accessibility: Waiting times in Canada are longer than in many countries with universal health care. "Delayed care is by definition care of lesser quality," said Doig.

- Portability: Rules regarding the portability of health coverage are inconsistent across all provinces. With more Canadians moving between provinces seeking work, the "expectations for our health insurance coverage should mirror the expectations for personal and professional mobility," said Doig.

- Public administration: There is a lack of clarity about how the government makes administrative decisions, said Doig, which makes it difficult to assess the value-for-money provided by medicare. These decisions should be more transparent because all "Canadians have a right to know how their system is performing."

Doig noted that, despite the challenges facing medicare in Canada, some provinces have been leading the way in improving the health care system. These include British Columbia, which is moving to a patient-focused funding model; Saskatchewan, which has launched an initiative to reduce surgical wait times; and Quebec, which is introducing a program to promote transparency in health funding.

"What we need now is a sustained effort to support these local good ideas and translate them into broader, national improvements," said Doig. Roger Collier, CMAJ

DOI:10.1503/cmaj.109-3261 